\title{
Einwirkungen des kalten Winters 1962/63 auf die Bakterienpopulationen vor Helgoland
}

\author{
WILFRIED GUNKEL \\ Biologische Anstalt Helgoland, Meeresstation, Helgoland
}

\begin{abstract}
Effects of the cold winter 1962/63 on the bacteria populations of Helgoland. In order to count the total number of bacteria, the pour-plate method and a modified $2216 \mathrm{E}$ medium (ZoneLL 1946) were used; temperature and salinity were recorded. Two cruises were conducted: one in the direction of the estuary of the river Elbe, the other in the direction of the open North Sea (light-ship P 8, located 25 nautical miles westwardly from Helgoland). The highest bacterial numbers were found at the stations closest to the mainland, and a close correlation between temperature, salinity and bacterial numbers was discovered. In other words, coastal water high in bacterial numbers and rich in organic substances was mixed with water of the open sea with a low bacterial content. To some extent transportation of bacteria via ice floes is responsible for the high bacterial numbers in the colder water. During the warm-up periods in early spring of 1963, a sharp increase in bacterial numbers was found in the samples taken in the waters at the permanent station between Helgoland and the nearby Dune. These numbers correspond with a decrease in salinity. The bacterial curves are to some extent in agreement with those found in the river Elbe in the winter and spring of 1963 by Rheinheimer (1964). From all these facts it becomes apparent that the bacterial numbers recorded near Helgoland are strongly influenced by the water of the river Elbe, and therefore the effects of the cold winter 1962/63 upon bacteria of the coast of Helgoland are to an important part indirect ones.
\end{abstract}

\section{EINLEITUNG}

Wassertemperaturen, wie sie der außerordentlich strenge Winter 1962/63 mit sich brachte, gehören in unserem Untersuchungsgebiet um Helgoland zu den Seltenheiten. Es lag daher nahe, die Auswirkungen der extrem niedrigen Temperaturen auf die marinen Bakterienpopulationen im Gebiet um Helgoland näher zu studieren. Die Auswertung der gewonnenen Informationen ist noch in vollem Gange. Ich muß mich hier daher auf einen Bericht über die ersten Teilergebnisse beschränken.

\section{METHODIK}

Die Keimzahl wurde mit Hilfe des bewährten Gußplattenverfahrens und einer Methode-bestimmt, die ich seit einigen Jahren bei meinen Untersuchungen in der Deutschen Bucht angewandt habe (Gunkel 1963). Als Nährboden wurde das Seewassermedium $2216 \mathrm{E}$ (ZoBell 1946) in etwas abgewandelter Form eingesetzt. Es 
hatte folgende Zusammensetzung: Difco Bacto Peptone $5 \mathrm{~g}$; Difco Bacto Yeast Extract $1 \mathrm{~g} ; \mathrm{FePO}_{4} \times 2 \mathrm{H}_{2} \mathrm{O} 0,01 \mathrm{~g}$; Difco Bacto Agar $15 \mathrm{~g}$; gealtertes Seewasser $750 \mathrm{ml}$; Aqua destillata $250 \mathrm{ml}$. Die Nährböden wurden in genau abgemessenen Mengen von $10 \mathrm{ml}$ (Gunkel, Jones \& Zobell 1960, 1961) und einer Temperatur von $42^{\circ} \mathrm{C}$ zum Gießen der Platten benutzt. Die Proben stammten von: 1) der Terminstation "Kabeltonne" zwischen der Insel Helgoland und der ihr benachbarten Düne; 2) zwei Schnittfahrten mit dem Forschungskutter "Uthörn" (die See war bei extrem ruhigem Wetter mit Eisfeldern bedeckt); 3) einer Eisscholle sowie dem Umgebungswasser vor der Helgoländer Landungsbrücke.

\section{UNTERSUCHUNGSERGEBNISSE}

Abbildung 1 zeigt den Temperaturverlauf während der Jahre 1962 und 1963 an der Helgoländer Kabeltonne, welche zwischen der Insel Helgoland und der Düne gelegen ist. Die Messungen wurden, soweit es die Witterung zuließ, in zweitägigen Intervallen durchgeführt. Die Winterkurve für 1962 weicht stark von der für $1963 \mathrm{ab}$. Im Jahre 1962 trat das Temperaturminimum am 15. März auf mit $+2,1^{\circ} \mathrm{C}, 1963 \mathrm{da}-$

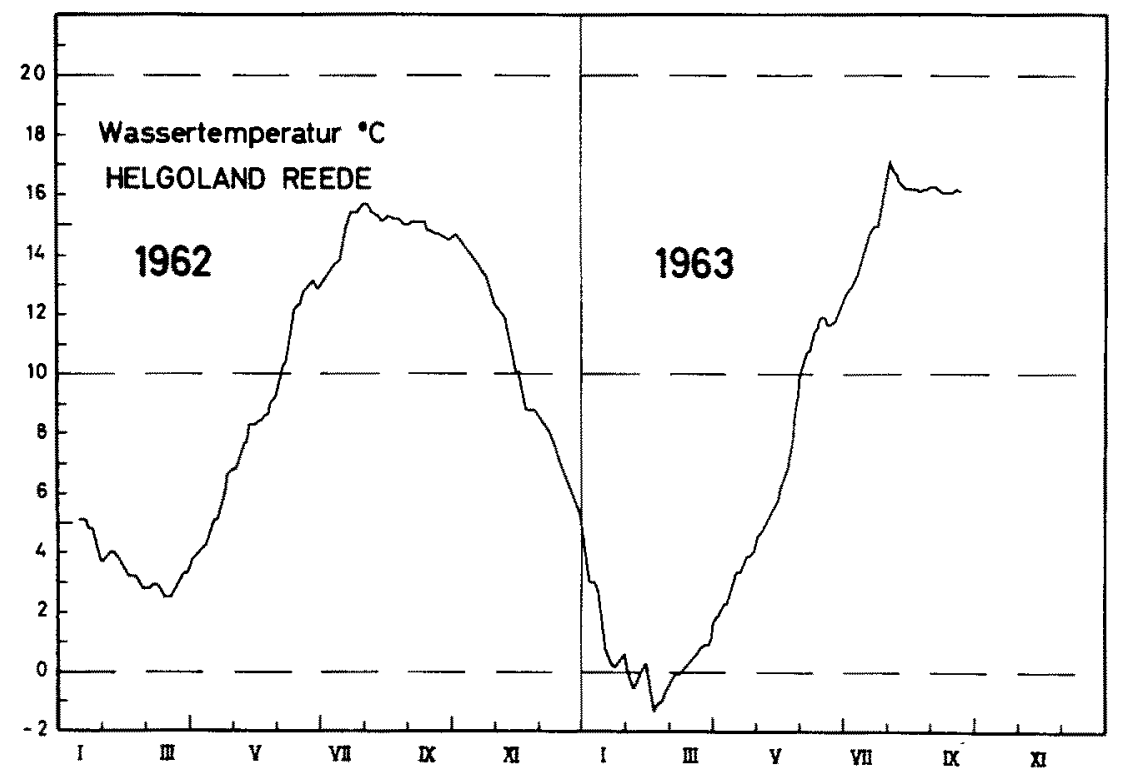

Abb. 1: Oberflächentemperaturen bei Helgoland (Kabeltonne, Helgoländer Reede) in den Jahren 1962 und 1963. 10fach übergreifende Mittel

gegen am 20. Februar mit $-1,6^{\circ} \mathrm{C} .1963$ wurde das Wasser also um 3,70 $\mathrm{C}$ kälter. Im Frühjahr 1963 ging der Temperaturanstieg sehr rasch vor sich. Bereits Mitte Mai 1963 wurde eine höhere Temperatur als im Vorjahr erreicht.

Abbildung 2 gibt die Bakterienzahlen pro $\mathrm{ml}$ an der Kabeltonne für 1962 und 1963 wieder. Die Daten basieren auf Untersuchungen, in deren Verlauf 243 Proben aufgearbeitet und 3645 Petrischalen angelegt wurden. In beiden Jahren ist die Grund- 
tendenz der Kurven bis zu einem gewissen Grade ähnlich. Während das Maximum der Bakterienentwicklung 1962 jedoch vor der Erreichung des - hier bedeutend höher liegenden - Temperaturminimums liegt, erreichen die Werte für 1963 das Maximum erst nach dem Eintritt des Temperaturminimums bei $2,5^{\circ} \mathrm{C}$ am 5 . April. Das 1963-

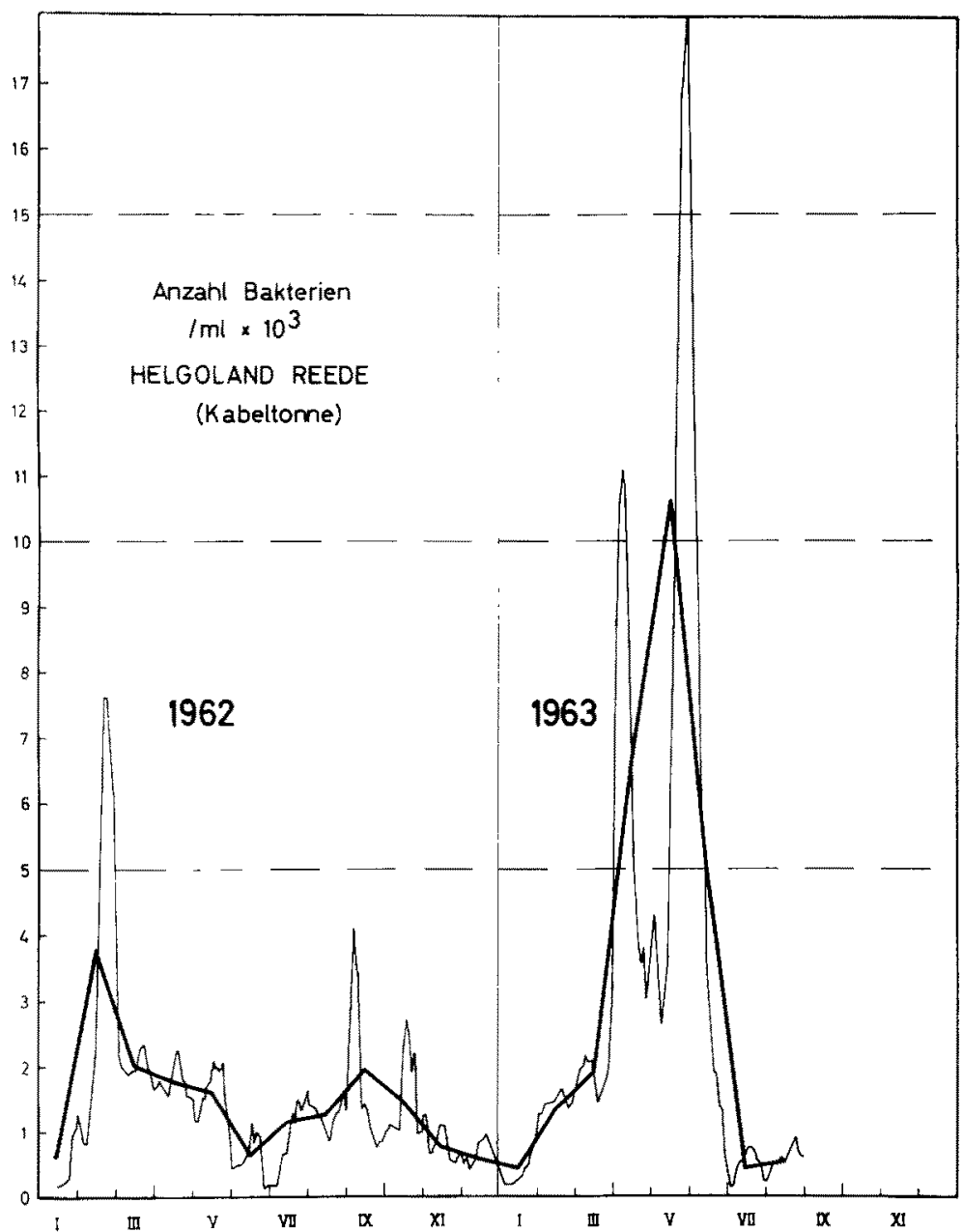

Abb. 2: Keimzahlen pro $\mathrm{ml}$ in Wasserproben, welche an der Helgoländer Kabeltonne in den Jahren 1962 und 1963 entnommen wurden. Dünn ausgezogene Linie: übergreifendes 10tägiges Mittel; stark ausgezogene Linie: Monatsmittel

Maximum übertriff das des Vorjahres bei weitem. Ein zweites, noch höheres Maximum wurde $1963 \mathrm{mit}$ über $24000 \mathrm{Bakterien} / \mathrm{ml}$ am 27. Mai erreicht.

Die Abbildungen 3 und 4 zeigen die Bakterienverteilung für zwei Schnitte, von denen einer in Richtung auf das 15 Seemeilen südöstlich Helgoland gelegene Feuerschiff Elbe I und der andere in Richtung auf das 25 Seemeilen westlich von Helgoland gelegene Feuerschiff P 8 verläuft. Auf beiden Schnitten wurden insgesamt 37 Wasser- 
proben entnommen und sofort an Bord $370 \mathrm{Gußplatten} \mathrm{angelegt.} \mathrm{Die} \mathrm{Fahrt} \mathrm{ging} \mathrm{durch}$ mehrere Eisfelder, bis die Stärke des Eises bei Feuerschiff Elbe I ein weiteres Vordringen unmöglich machte. Da die Fahrten an zwei aufeinanderfolgenden Tagen durchgeführt wurden, ist ein unmittelbarer Anschluß nicht möglich. Während wir auf den

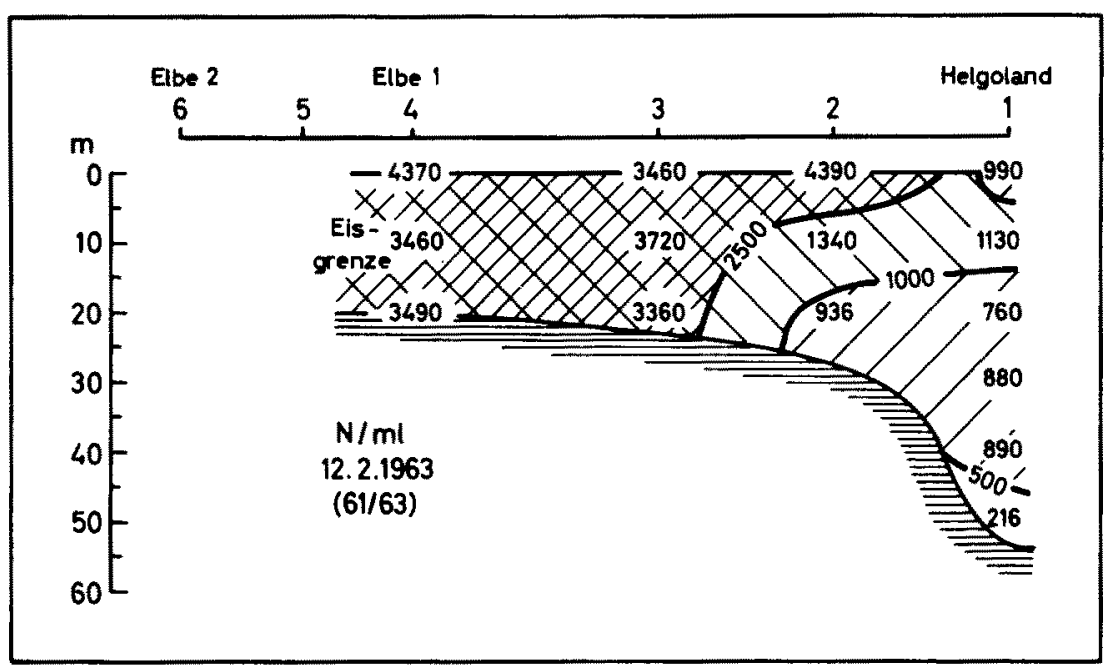

Abb. 3: Verteilung der Bakterien pro ml auf dem Sdnitt Helgoland - Feuerschiff Elbe 1 am 12. Februar 1963

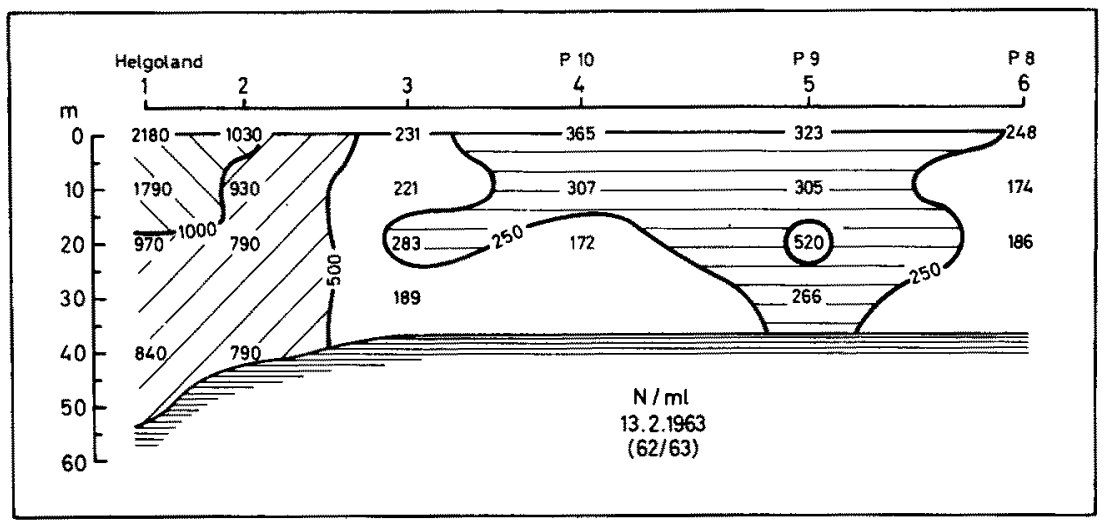

Abb. 4: Verteilung der Bakterien pro $\mathrm{ml}$ auf dem Schnitt Helgoland - Feuerschiff P 8 am 13. Februar 1963

beiden landnächsten Stationen Bakterienzahlen von mehr als 3000/ml finden, nimmt diese Zahl nach Helgoland hin ab, und zwar zunächst in den Tiefen (Station 2). Bei Station 1 liegen bis auf die 10-m-Probe alle Werte unter 1000/ml. Auf dem zweiten Schnitt nach Feuerschiff P 8 verstärkt sich diese Tendenz. Zunächst werden noch höhere Werte in den Oberflächenproben festgestellt, bis dann ab Station 3 Werte von um 200 bis $300 \mathrm{Bakt} / \mathrm{ml}$ erhalten werden. 
Interessant ist hierzu ein Vergleich mit der gleichzeitig gemessenen Temperatur ${ }^{1}$, dargestellt in den Abbildungen 5 und 6. Die niedrigsten Werte wurden auf dem Schnitt zur Elbe auf den Stationen 4 und 5 gemessen. Ein stärkerer Gradient tritt bei den Stationen um Helgoland auf, wobei in ständig zunehmendem Maße vom Boden her

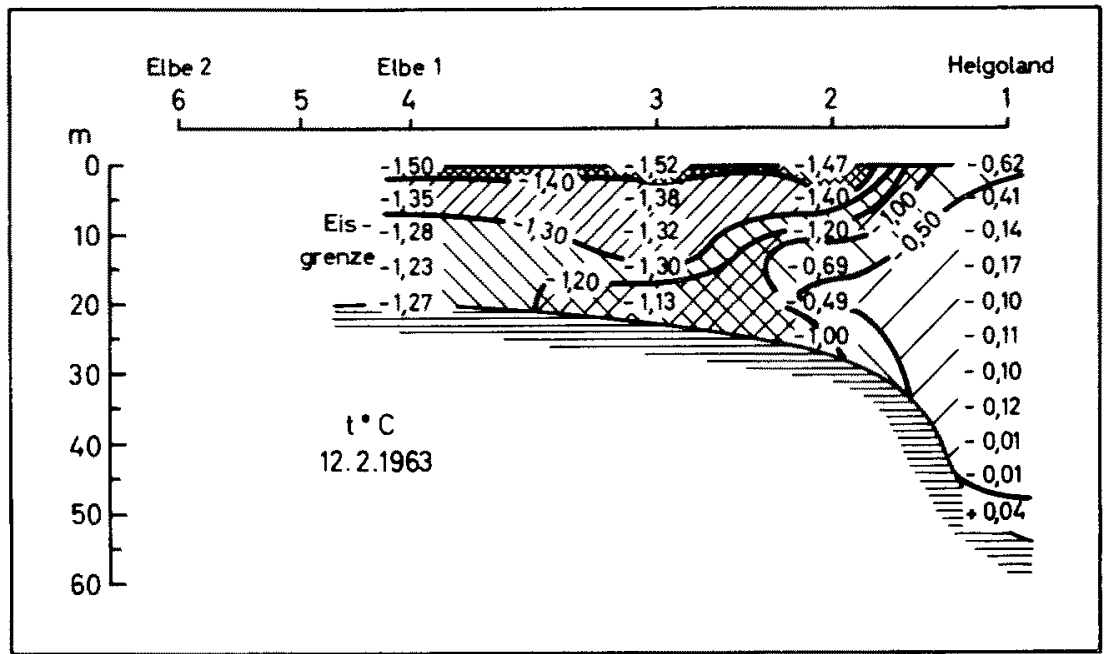

Abb. 5: Temperaturverhältnisse auf dem Schnitt Helgoland - Feuerschiff Elbe 1 am 12. Februar 1963

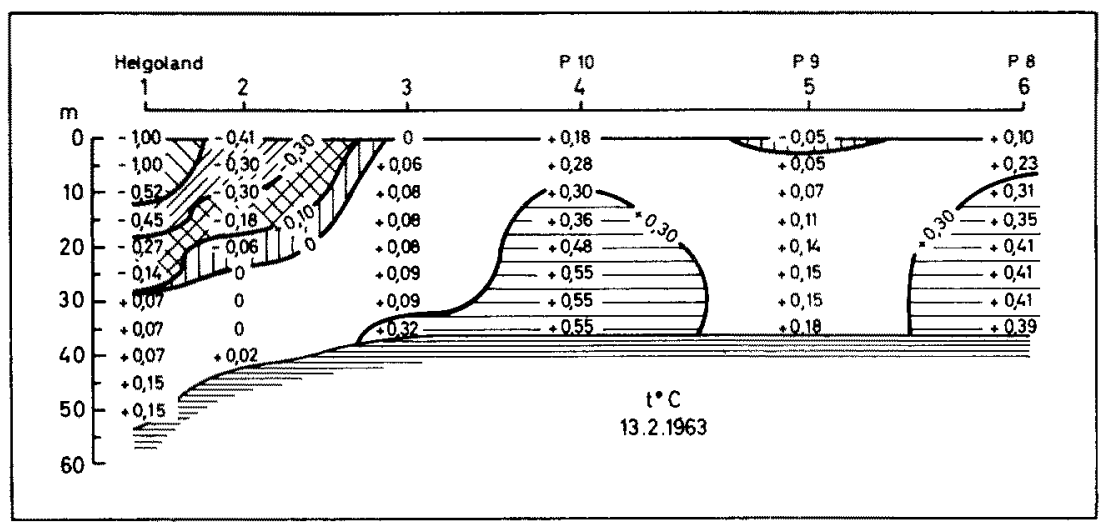

Abb. 6: Temperaturverhältnisse auf dem Schnitt Helgoland - Feuerschiff P 8 am 13. Februar 1963

wärmeres Wasser an Mächtigkeit gewinnt, so daß mit der Ausnahme eines Wertes ab Station 3 keine Minustemperaturen mehr angetroffen werden, $d$. h. je höher die Temperatur desto geringer wird die Anzahl feststellbarer Bakterien. Diese hier vorliegende Beziehung wird noch deutlicher beim Auftragen der Bakterienzahl gegen die Tempe-

\footnotetext{
1 Die Temperaturwerte stellte freundlicherweise Herr Dr. Gillaricht zur Verfügung.
} 
ratur (Abb. 7) beziehungsweise den Salzgehalt ${ }^{2}$ (Abb. 8). Da Temperatur und Salzgehalt gekoppelt sind, besteht diese Beziehung auch in diesem Falle.

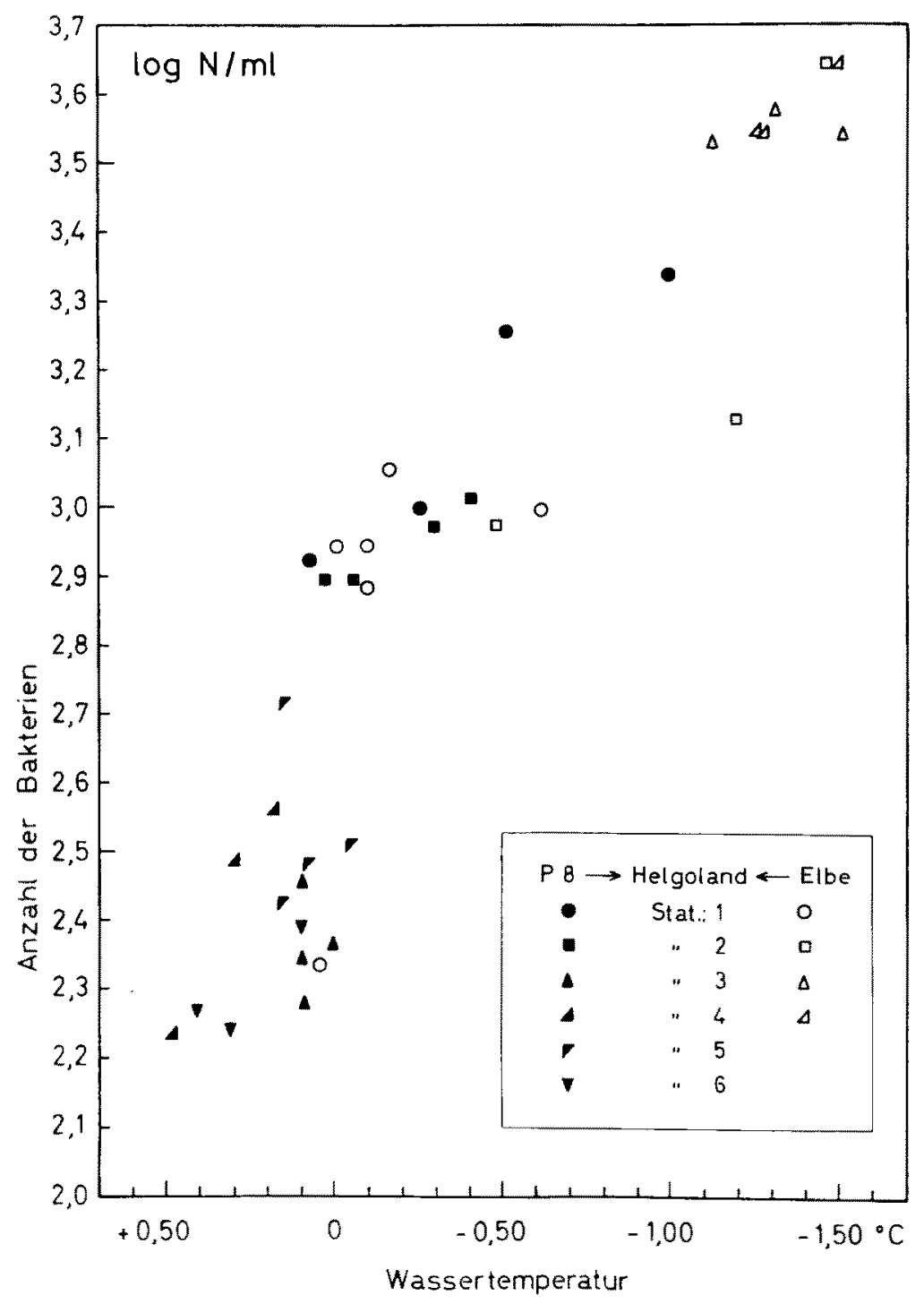

Abb. 7: Beziehungen zwischen Bakterienzahl und Temperatur auf den Schnitten Feuerschiff Elbe 1 - Helgoland und Feuerschiff P 8 - Helgoland

Zum Abschluß sei das Ergebnis eines weiteren Versuches mitgeteilt. Am 7. Februar 1963 war das Wasser um Helgoland von einer geschlossenen Decke zusammengeschobener Eisschollen bedeckt, nur zwischen Insel und Düne war etwas freies Wasser vorhan-

${ }^{2}$ Die Salzgehaltsbestimmungen wurden vom Deutschen Hydrographischen Institut Hamburg durchgeführt. 
den. Es wurde eine Eisscholle von der Landungsbrücke aus entnommen und ihr Keimgehalt mit $2580 \mathrm{Bakt} / \mathrm{ml}$ auf Seewasseragar bestimmt. Das umgebende Wasser hatte einen Keimgehalt von $1720 \mathrm{Bakt} . / \mathrm{ml}$ und eine Temperatur von $-1,7^{\circ} \mathrm{C}$. Neben dem Seewassernährboden wurde auch ein mit Aqua destillata bereiteter Nähragar verwendet. Hier wurden bei der Eisprobe 66, bei der Seewasserprobe 163 Bakterien pro ml erhalten.

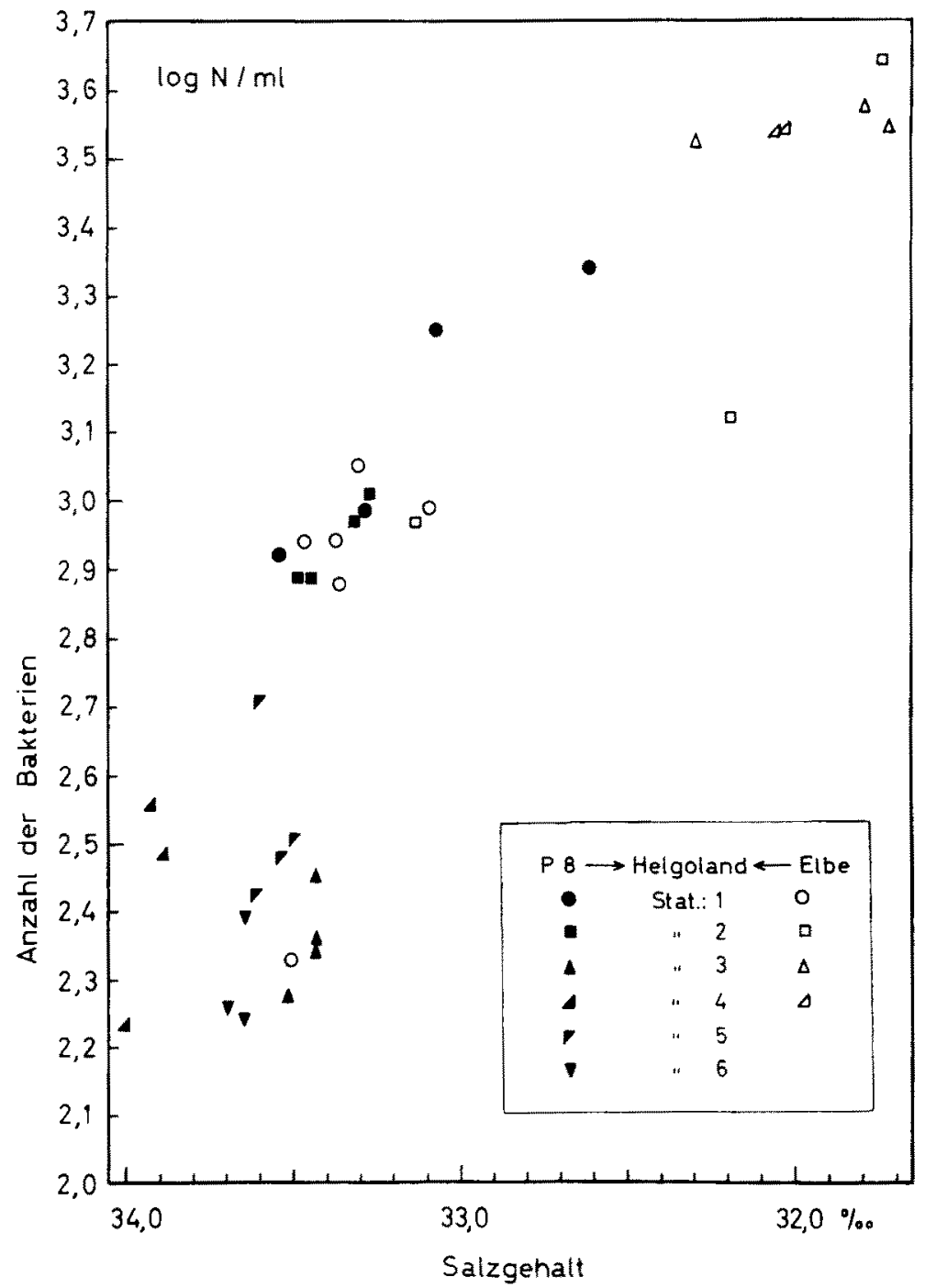

Abb. 8: Beziehungen zwischen Bakterienzahl und Salzgehalt auf den Schnitten Feuerschiff Elbe 1 - Helgoland und Feuerschiff P 8 - Helgoland 


\section{DISKUSSION}

\section{Kabeltonne}

Es ist bisher nicht möglich, den ganzen Verlauf der Jahreskurve der Bakterienzahl an der Kabeltonne mit bestimmten Umweltfaktoren eindeutig in Beziehung zu setzen. Dazu müßten Untersuchungen über eine ganze Reihe von Jahren vorliegen. Erst langfristige und umfangreiche Untersuchungsreihen - so dürfen wir hoffen - werden es uns einst ermöglichen, Zufälligkeiten und Gesetzmäßigkeiten klar zu unterscheiden. Besonders kompliziert werden die Verhältnisse dadurch, daß wir ja nur selten in dem gleichen Wasserkörper messen können. Je nach Stromrichtung geraten wir in andere Wasserkörper, so daß auch die Einwirkungen, die zu einer Veränderung der Bakterienzahl führen, nur kurzzeitig und in wechselnder Intensität auftreten. Wir befinden uns mit Helgoland gerade in der Konvergenzzone von Küstenwasser und eigentlichem Nordseewasser (GoEDECKE 1955).

Das erste Maximum der Bakterienzahl im Jahre 1963 fällt zusammen mit einer Phytoplanktonblïte (GILlBRICHT 1964), einer besonders intensiven Erwärmungs-

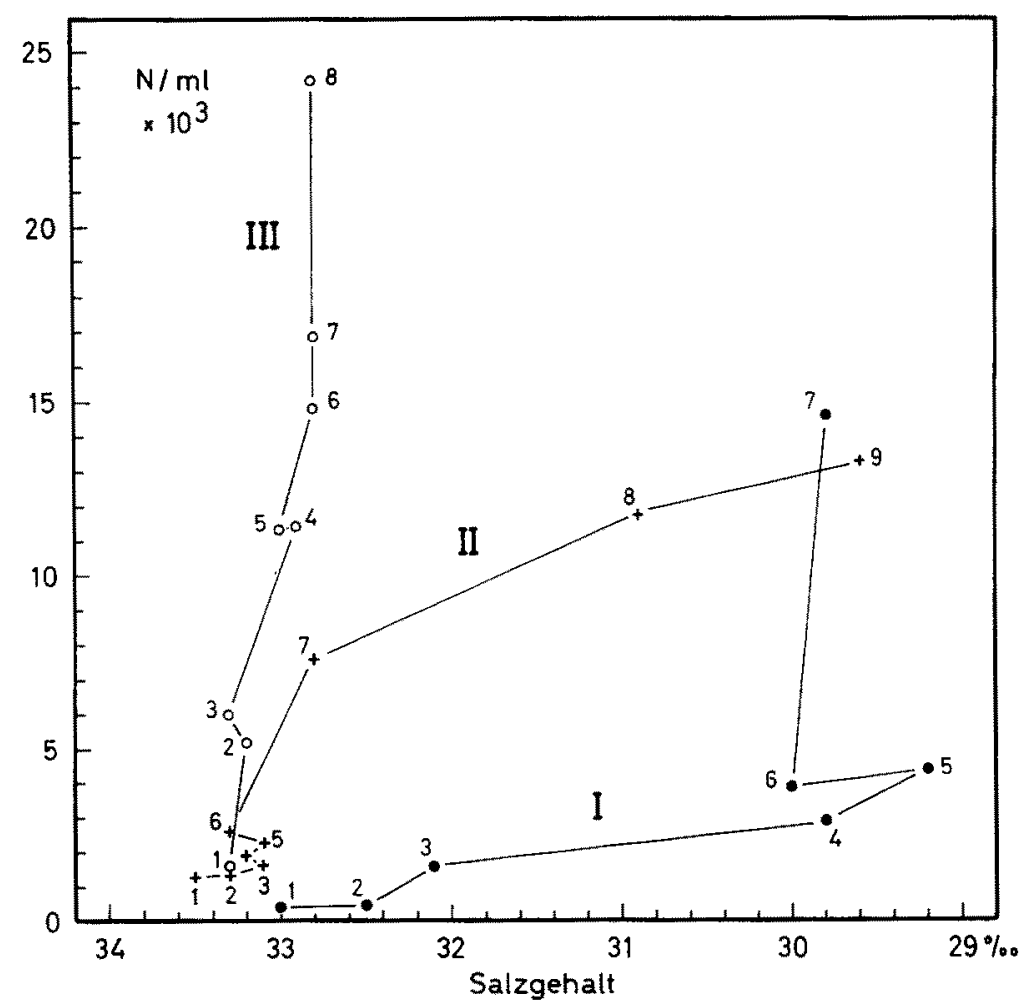

Abb. 9: Beziehungen zwischen Salzgehalt und Bakterienzahl zu Zeiten maximaler Bakterienzunahme. I: im Februar 1962, II: im März/April 1963; III: im Mai 1963. Die arabischen Ziffern geben die zeitliche Aufeinanderfolge der Proben an. Die Wasserproben stammen von der Helgoländer Kabeltonne 
phase (Abb. 1) und einer sehr starken Abnahme des Salzgehaltes, d. h. Beimengung von Süßwasser, das fast ausschließlich aus der Elbe stammen dürfte (Abb. 9). Frühere nicht veröffentlichte Untersuchungen hatten keine positive Korrelation zwischen Phytoplankton und Bakterien ergeben. Aus diesem Grunde müssen wir die Beimengung von nährstoffreichem Süßwasser für die Zunahme der Bakterien verantwortlich machen. Eine gewisse Rolle könnten aber auch organische Substanzen spielen, die durch das Absterben der Bodenfauna (ZIEGELMEIER 1964), hervorgerufen durch die extrem niedrigen Wassertemperaturen, frei wurden. Wir können annehmen, daß, auf diesen Voraussetzungen basierend, die intensive Erwärmung ihren Teil beitrug, um zu den erhaltenen hohen Bakterienzahlen zu kommen.

Interessant ist ein Vergleich mit den Daten, die in der Elbe gefunden wurden (RhernheImer 1964). Auch er findet im Winter $1962 / 63 \mathrm{ganz}$ allgemein bedeutend höhere Bakterienzahlen und höhere Maxima als im Vorjahr. Die Maxima in der Elbe liegen zeitlich mehrere Wochen vor dem Helgoland-Maximum. Auf 7 Elbstationen erhielt RHEINHEIMER zwischen 176000 und 623000 Bakterien/ml. Da das Elbewasser mehrere Wochen benötigt, um Helgoland zu erreichen, ist durchaus denkbar, daß es die Ursache für die bei Helgoland zur Zeit des zweiten Maximums aufgetretene Salzgehaltsabnahme auf $32,8 \%$ darstellt. Wir müßten dann - bei einem Salzgehalt des inneren Nordseewassers von $35 \%$ - ca. 11000 bzw. 39000 Bakt./ml erwarten, also Werte, die der Größenordnung unseres Maximums (24 $200 \mathrm{Bakt} . / \mathrm{ml}$ ) tatsächlich entsprechen. Daß es sich bei den von uns festgestellten Bakterien um die gleichen Elbbakterien handelt, wäre jedoch eine zu sehr vereinfachende Annahme. Denn einmal ist inzwischen Zeit verstrichen, die Population hat sich verändert, und außerdem sind die Süßwasserbakterienpopulationen in ein salzhaltiges Milieu gelangt, wobei eine Adaptation stattgefunden haben dürfte, bzw. die Population ersetzt worden ist. Unser Maximum basiert ja auf Zahlen, die mit Hilfe von Seewassermedien festgestellt wurden. Gleichzeitig mit Aqua-destillata-Medien angelegte Kulturen lieferten bedeutend geringere Werte, obwohl auch hier Ende Mai ein Maximum mit $2100 \mathrm{Bakt} / \mathrm{ml} \mathrm{er-}$ reicht wurde, das in Höhe von $16 \%$ der Seewasserwerte liegt. Hier müssen weitere Untersuchungen durchgeführt werden, insbesondere im Hinblick auf denjenigen Teil der organischen Substanz, der von Bakterien leicht verwertet werden kann. Gegenwärtig erscheint die Annahme berechtigt, daß die hohen Bakterienzahlen vor Helgoland zu Beginn des Jahres 1963 großenteils über die Einflüsse des kalten Winters auf die Elbe zustande gekommen sind.

\section{Schnittfabrten}

Klarer liegen die Verhältnisse auf den beiden Schnittfahrten: Das kältere Küstenwasser ist keimreicher, und der verschiedene Grad der Durchmischung mit wärmeten, keimärmerem Nordseewasser ergibt die verschiedenen erhaltenen Keimzahlen, d. h. die Temperatur ist hier wie der Salzgehalt Indikator für den Wasserkörper, nicht etwa, daß die niedere Temperatur ihnen bessere Wuchsbedingungen schafft.

Neben dem Elbwassereinfluß dürfte eine beträchtliche Rolle die Keimverfrachtung durch das Eis spielen. Die untersuchte Eisscholle war rein weiß und ohne Einschlïsse. 
Es sollte gewissermaßen einmal die untere Keimzahlgrenze im Eis festgestellt werden. Dabei wurden dann, wie bereits angeführt, $2580 \mathrm{Bakt} / \mathrm{ml}$ gefunden, also ein höherer Wert als im umgebenden Wasser $(1720 \mathrm{Bakt} / \mathrm{ml})$. Ein großer Teil der Eisschollen war aber dunkel gefärbt von eingefrorenen Schlick- und Sandteilchen, teilweise waren richtige Schlickbrocken eingefroren. Hier hätten wir noch wesentlich höhere Zahlen an Bakterien erhalten. HöHNK (1958) gelang es übrigens, aus Eisschollen 21 verschiedene Pilzformen herauszuködern. Der Schlickgehalt ist nicht weiter verwunderlich, da der größte Teil des Eises auf den ausgedehnten Wattflächen entsteht. Da beim Gefriervorgang salzhaltiges Wasser ausgepreßt wird, die Eisschollen somit einen niedrigeren Salzgehalt haben (eine geschmolzene Eisscholle ergab den Wert von 5,39\% gegen-

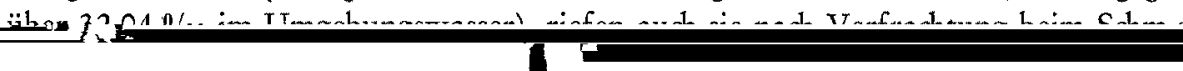


Höнnk, W., 1958. Mykologische Notizen: I. Mikropilze im Eis. Veröff. Inst. Meeresforsch. 5, $193-194$.

Rheinheimer, G., 1964. Einwirkungen des kalten Winters 1962/63 auf die Bakterienpopulation der Elbe. Helgol. Wiss. Meeresunters. 10, im Druck.

ZiegelmeIER, E., 1964. Einwirkungen des kalten Winters 1962/63 auf das Makrobenthos im Ostteil der Deutschen Budht. Helgol. Wiss. Meeresunters, 10, im Druck.

Zobell, C. E., 1946. Marine microbiology: a monograph on hydrobacteriology. Chronica Botanica, Waltham, Mass., 240 pp. 